\title{
Trade-off Between Quality, Price, and Profit Orientation in Germany's Nursing Homes
}

\author{
Max Geraedts ${ }^{1}$ - Charlene Harrington ${ }^{2}$. \\ Daniel Schumacher ${ }^{1} \cdot$ Rike Kraska $^{1}$
}

Published online: 17 October 2015

C The Author(s) 2015. This article is published with open access at Springerlink.com

\begin{abstract}
International data suggest that for-profit nursing homes tend to provide lower quality than not-for-profit nursing homes. In Germany, the relationships between profit orientation, price and quality of nursing homes have not been investigated. We performed an observational study using secondary data from statutory quality audits of all nursing homes in Germany. The relationships were analyzed bivariately via Mann-Whitney $U$-Test and Kruskal-Wallis Test respectively, followed by a multivariate variance analysis which also covered the interaction effect between quality, price and type of ownership. $41 \%$ of 10,168 German nursing homes were for-profit charging on average about $10 \%$ less than not-for-profit homes. In five out of six quality categories under study, for-profit nursing homes provided lower quality than not-forprofit homes. Quality of care in all quality categories improved with increasing prices per day. However, for four out of six quality categories examined, the quality difference between for-profit and non-profit nursing homes existed independent of the price charged. When selecting a nursing home it is therefore advisable to consider the profit orientation of the institution. German legislation should require that statutory public quality reports contain details on the profit orientation of nursing homes.
\end{abstract}

Keywords Nursing homes · Germany · Ownership · Profit orientation · Quality of care

Max Geraedts

max.geraedts@uni-wh.de

1 Institute for Health Systems Research, School of Medicine, Faculty of Health, Witten/Herdecke University, Alfred-Herrhausen-Strasse 50, 58448 Witten, Germany

2 Department of Social and Behavioral Sciences, University of California, San Francisco, 3333

California St., Suite 410, San Francisco, CA 94143, USA 


\section{Introduction}

Germany, like other industrialised nations, is faced with a steadily increasing risk of need for long-term-care services as a consequence of demographic change. A growing number of people in old age depend on support for activities of daily living (ADL). Most citizens prefer to receive care in their own homes, but towards the end of life many cannot manage without in-patient care in a nursing facility. A growing number of citizens must address the question as to which nursing home is suitable for their individual requirements.

In Germany an obligatory audit for all nursing homes that was introduced in 2009 facilitates this choice; the health insurance funds' medical service departments evaluate institutional care facilities at least once per year on site, based on a statutory checklist of 82 criteria. Nursing homes are required by law to display audit results on the premises, and statutory nursing insurance funds publish all results via internet.

Long-term-care (LTC) insurance was introduced in Germany in 1995 as a mandatory element of all statutory and private health insurance schemes (Geraedts et al. 2000), so that the entire population is now protected against long-term-care costs. Concurrent with the introduction of LTC insurance, the government started to promote the building and expansion of outpatient and inpatient long-term-care facilities. In this context state funding was available to public non-profit or charitable providers of long-term-care as well as private for-profit providers. As a consequence, the share of for-profit providers of nursing care among outpatient nursing services in Germany increased from 51 to $64 \%$, and among nursing homes from 35 to $41 \%$ between 1999 and 2013 (Statistisches Bundesamt 2001, 2014).

In a market they share with non-profit providers, for-profit providers of nursing care have to contend with the basic problem of higher capital costs, which may partially be offset by more efficient management, higher prices or diminishing service quality levels. It is generally difficult for users to assess service quality in the case of experience or credence goods such as nursing services. This is why for-profit providers might be induced to deliberately compromise quality in favour of profit maximisation in this sector (Hansmann 1980). Moreover, the most efficient strategy appears to be cost leadership, since other basic competitive strategies such as differentiation and niche strategies are not very promising in a market shared with not-for-profit service providers (Porter 1980). International literature on the correlation between profit orientation of nursing homes and the quality of services provided supports the evidence of these theoretical reflections for the most part. In a meta-analysis, Comondore et al. (2009) concluded that nonprofit nursing homes generally provide better care compared to for-profit nursing homes. More recent studies confirm the theoretically expected behaviour on the part of for-profit nursing care providers (Harrington et al. 2012, Harrington et al. 2015). Based on the convincing data available, the US Center for Medicare Advocacy advises consumers to consider profit orientation in the choice of a nursing home, and to select a not-for-profit nursing care facility (Medicare Advocacy 2015).

In view of the above, this study aimed to explore the correlation between profit orientation of German nursing homes, their prices and the quality of care provided. 


\section{Methods}

The study was designed as a cross-sectional study based on secondary data. Data sources, operationalisation of variables and analytical procedures are described in the following.

Nursing Homes The study was based on the most up-to-date assessments of all German nursing homes in the years 2011 and 2012 respectively from the statutory quality audits performed by the health insurers' medical service departments. Data were provided by Germany's largest nursing care insurer, the national sickness fund association AOK (Allgemeine OrtsKrankenkasse), and cover a total of $N=10,471$ nursing homes offering full inpatient care. Excluded from these data were homes specializing in vigil coma patients $(N=36)$, those with no identifiable type of ownership $(N=43)$, homes with incomplete quality data by more than $50 \%(N=2)$, or with no data on monthly charges for nursing care $(N=222)$. The number of nursing homes remaining for the analysis was $N=10,168$.

Profit Orientation Data on the type of ownership were available for each nursing home under consideration. A distinction was made between private for-profit institutions and public not-for profit and charitable facilities. Because only $5 \%$ of all German nursing homes have public ownership, they were combined with charitable homes in the not-for-profit category for the analysis.

Prices Available cost details for each facility cover daily costs for nursing care, room and board. Investment costs which nursing homes charge to each home resident proportionally and on a small scale are not included in the data and therefore do not enter price calculations for each care facility. Moreover, prices per resident depend on the extent of care required. Residents are assigned to one of three care levels; the national distribution of care levels in nursing homes is as follows: care level 1 (lowest) $38.12 \%$, care level 2 (medium) $-40.29 \%$, care level 3 (highest) $-20.45 \%$. The percentage per nursing home of care recipients assigned to care levels 1 to 3 was not given, so that an equal distribution was assumed, and the daily price per nursing home was calculated as weighted mean of the national distribution.

Average prices charged by nursing homes differ greatly between the 16 federal states in Germany. This is why 5 price categories per federal state were set up with approximately equal numbers of nursing homes for the calculation of correlations between prices and quality of service. As a next step all nursing homes in each of the five price categories were summarized across the nation, and the price was used for analysis as a categorical variable.

Quality of Care To assess the quality of care provided in nursing homes the authors used evaluations from the health insurers' medical service departments collected in unannounced audits in 2011/2012. Audits are based on a checklist of 82 criteria (GKVSpitzenverband 2008). Eighteen criteria relate to satisfaction surveys among home residents; 38 criteria are determined from a sample of 5-15 residents, depending on the size of the facility; the remaining criteria are assessed per facility. In case of resident-related criteria, the values for individual residents are summed up to form a 
final value per criterion on a scale from 1 to 5. Facility-related criteria are dichotomous, i.e., registered as either existent or non-existent.

For the purposes of this study, criteria were assigned in terms of content to the following categories: facility structure (4 criteria, e.g., "secured recreational areas outside", "food and drinks provided in a pleasant environment"), nursing processes (23 criteria, e.g., "required pressure sore prophylaxis is implemented", "systematic pain assessments conducted", "biography of residents suffering dementia taken into account and being considered when planning daily activities"), support procedures (16 criteria, e.g., "contact with relatives ensured", "assistance or information provided to familiarize new residents with the nursing facility"), documentation of nursing services ( 7 criteria, e.g., "individual risk of falling registered", "individual risks and resources of residents with incontinence or a bladder catheter assessed"), patient outcomes (2 criteria, "nutritional status appropriate", "supply of fluids appropriate") and quality management (5 criteria, e.g., "written instructions available on how to proceed in emergencies", "nursing facility has a system for managing complaints"). Five criteria were not included in the analysis since over $50 \%$ of pertinent data were not available. Inclusion of two further criteria was not possible since the underlying scale did not permit assignment to suitable content categories. Criteria related to surveyed resident satisfaction were not used either, since these surveys were performed on the basis of a non-validated interview tool and with an insufficient case number and sample size in most cases (Hasseler et al. 2010).

Statistics The relationships between profit orientation and prices charged by nursing homes on the one hand, and quality of care on the other were first determined bivariately via Mann-Whitney $U$-Test and Kruskal-Wallis Test respectively, followed by a multivariate variance analysis which also covered the interaction effect between price and type of ownership. Additionally, post hoc tests with Bonferroni-Holm correction for multiple testing were performed to discover the trend of correlations between variables in detail. The statistics software SPSS version 22 was used for all descriptive and analytical evaluations.

\section{Results}

Table 1 shows the absolute and relative frequency of for-profit and non-profit nursing homes in Germany and average daily prices for long-term-care services, room and board. Daily rates charged by the $40 \%$ for-profit homes undercut those charged by non-profit facilities by an average of $€ 9.17$, i.e., more than $10 \%$.

Table 2 lists the average prices charged per day by nursing homes in the five price categories. The large spans result from the pooling of nursing homes from different federal states. The two quintiles 1 and 2 with lowest costs comprise $69 \%$ of for-profit homes but only about $20 \%$ of non-profit facilities.

Table 3 illustrates the bivariate correlation between profit orientation of nursing homes and the quality of care provided. With the exception of the category "patient outcomes" with only two single criteria, the Mann-Whitney $U$-Test reveals highly significant differences in all other quality categories: non-profit nursing homes consistently provide better quality of care compared to for-profit facilities. 
Table 1 Frequency and price per day of for-profit and non-profit nursing homes in Germany

\begin{tabular}{lllllll}
\hline & \multicolumn{2}{l}{ For-Profit Nursing Homes } & & \multicolumn{2}{l}{ Non-Profit Nursing Homes } & \multirow{2}{*}{ Total } \\
\cline { 2 - 3 } & $\mathrm{N}$ & $\%$ & & $\mathrm{~N}$ & $\%$ & \\
\hline Frequency & 4179 & 41.1 & & 5989 & 58.9 & 10,168 \\
& Mean & $\mathrm{SD}^{*}$ & & Mean & SD & Min-Max $^{\#}$ \\
Average price per day & $71.59 €$ & $9.43 €$ & & $80.76 €$ & $13.09 €$ & $35-549 €$ \\
\hline
\end{tabular}

*SD standard deviation, Min-Max ${ }^{\#}$ minimum - maximum price per day

Table 4 shows the bivariate correlation between the five price quintiles and quality categories. The effect that the service quality in German nursing homes increases with increasing prices applies to all categories.

Table 5 shows the results of the multi-variate variance analysis. The figure below additionally illustrates correlations between prices charged by nursing homes, profit orientation and the six quality categories examined (see figure). Irrespective of profit orientation, the quality of care in all quality categories improves with increasing prices per day, the same as in the bivariate analysis. However, profit orientation cannot be considered as independent of the price in all quality categories. In the categories of nursing processes, support services, quality management and structures, for-profit homes perform worse than non-profit institutions, independent of the price charged. No correlations were found, however, between documentation quality and outcomes on the one hand and profit orientation of the facilities on the other if the price charged by the nursing homes is taken into consideration (see Table 5).

Significant interactions between price and type of ownership were found for the criteria support services, quality management and structures. The three graphs on the right side of the figure below illustrate that for-profit nursing homes effect stronger quality improvement between the 1 st and 2 nd quintiles compared to non-profit homes (see figure). But for-profit homes achieve a higher quality level than non-profit homes in only one quintile for these categories.

Across all six quality categories, the level of quality in for-profit nursing homes is lower than in non-profit homes in 23 out of 30 comparable price quintiles. Additional post hoc tests with Bonferroni-Holm correction confirm the graphic impression that there are significant differences in relation to profit orientation

Table 2 Average price per day and number of for-profit and non-profit nursing homes per quintile

\begin{tabular}{llllllll}
\hline & Mean $€$ & Median $€$ & Min $€$ & Max $€$ & N & N for-profit & N non-profit \\
\hline Quintile 1 & 67.59 & 67.79 & 35.17 & 82.01 & 2029 & 1664 & 365 \\
Quintile 2 & 73.28 & 75.42 & 58.56 & 86.06 & 2033 & 1216 & 817 \\
Quintile 3 & 76.68 & 78.91 & 60.46 & 89.48 & 2033 & 738 & 1295 \\
Quintile 4 & 80.16 & 81.80 & 61.89 & 93.67 & 2033 & 362 & 1671 \\
Quintile 5 & 87.19 & 87.67 & 65.63 & 549.06 & 2040 & 199 & 1841 \\
Total & 76.98 & 78.32 & 35.17 & 549.06 & 10,168 & 4179 & 5989 \\
\hline
\end{tabular}


Table 3 Relationship between profit orientation and quality of care in nursing homes in Germany (MannWhitney $U$-Test)

\begin{tabular}{lccc}
\hline Quality category (No of criteria) & For-profit & Non-profit & $p$-value \\
\hline Nursing processes (23) & $4.29^{\mathrm{a}}$ & $4.40^{\mathrm{a}}$ & 0.000 \\
Documentation (7) & $4.49^{\mathrm{a}}$ & $4.58^{\mathrm{a}}$ & 0.000 \\
Outcomes (2) & $4.93^{\mathrm{a}}$ & $4.94^{\mathrm{a}}$ & 0.141 \\
Support services (16) & $97.75^{\mathrm{b}}$ & $98.95^{\mathrm{b}}$ & 0.000 \\
Quality management (5) & $93.20^{\mathrm{b}}$ & $96.26^{\mathrm{b}}$ & 0.000 \\
Structures (4) & $98.35^{\mathrm{b}}$ & $99.11^{\mathrm{b}}$ & 0.000 \\
\hline
\end{tabular}

a average value of all nursing homes on a scale from $1=$ worst to $5=$ best

${ }^{\mathrm{b}}$ average value of all nursing homes on a scale from $0 \%=$ worst to $100 \%=$ best

mainly in the lower price quintiles, whereas the upper price quintile does no longer reveal any statistically significant differences. It also appears that a good part of significant improvement happens up to the third price quintile across all quality categories, and the area beyond shows only consistently significant quality improvement for nursing processes.

Based on a summary of results shown in Tables 3,4 and 5 and the figure it must be acknowledged that all identified differences are at a low level and that nursing homes in general have received very good ratings. Therefore the multivariate model only explains approximately $3 \%$ in the variance of quality differences between for-profit and non-profit nursing homes, and between nursing homes of different price quintiles Fig. 1.

\section{Discussion}

All in all, for-profit nursing homes in Germany offer a lower service quality compared to non-profit nursing homes. One explanation for the differences is that for-profit homes charge lower prices on average and that the quality of nursing services is related

Table 4 Relationship between price per day quintiles and quality of care in nursing homes in Germany (Kruskal-Wallis Test)

\begin{tabular}{lcccccc}
\hline Quality category (No of criteria) & Quintile 1 & Quintile 2 & Quintile 3 & Quintile 4 & Quintile 5 & $p$-value \\
\hline Nursing processes (23) & $4.23^{\mathrm{a}}$ & $4.30^{\mathrm{a}}$ & $4.36^{\mathrm{a}}$ & $4.41^{\mathrm{a}}$ & $4.47^{\mathrm{a}}$ & 0.000 \\
Documentation (7) & $4.43^{\mathrm{a}}$ & $4.50^{\mathrm{a}}$ & $4.55^{\mathrm{a}}$ & $4.58^{\mathrm{a}}$ & $4.64^{\mathrm{a}}$ & 0.000 \\
Outcomes (2) & $4.92^{\mathrm{a}}$ & $4.93^{\mathrm{a}}$ & $4.94^{\mathrm{a}}$ & $4.94^{\mathrm{a}}$ & $4.95^{\mathrm{a}}$ & 0.009 \\
Support services (16) & $97.19^{\mathrm{b}}$ & $98.40^{\mathrm{b}}$ & $98.79^{\mathrm{b}}$ & $98.84^{\mathrm{b}}$ & $99.08^{\mathrm{b}}$ & 0.000 \\
Quality management (5) & $91.82^{\mathrm{b}}$ & $94.90^{\mathrm{b}}$ & $95.38^{\mathrm{b}}$ & $96.02^{\mathrm{b}}$ & $96.90^{\mathrm{b}}$ & 0.000 \\
Structures (4) & $97.86^{\mathrm{b}}$ & $98.82^{\mathrm{b}}$ & $98.93^{\mathrm{b}}$ & $99.07^{\mathrm{b}}$ & $99.29^{\mathrm{b}}$ & 0.000 \\
\hline
\end{tabular}

\footnotetext{
a average value of all nursing homes on a scale from $1=$ worst to $5=$ best

${ }^{\mathrm{b}}$ average value of all nursing homes on a scale from $0 \%=$ worst to $100 \%=$ best
} 
Table $5 P$-values and variance explained of the multivariate relationship between price per day quintiles, profit orientation and quality of care and their interactions in nursing homes in Germany

\begin{tabular}{llllr}
\hline Quality category (No of criteria) & Price per day & Profit orientation & $\begin{array}{l}\text { Price per day*profit } \\
\text { orientation }\end{array}$ & $\mathrm{R}^{2}$ \\
\hline Nursing processes (23) & 0.000 & 0.028 & 0.199 & 0.022 \\
Documentation (7) & 0.000 & 0.419 & 0.571 & 0.018 \\
Outcomes (2) & 0.001 & 0.373 & 0.894 & 0.003 \\
Support services (16) & 0.000 & 0.000 & 0.013 & 0.026 \\
Quality management (5) & 0.000 & 0.000 & 0.000 & 0.028 \\
Structures (4) & 0.005 & 0.004 & 0.011 & 0.009 \\
\hline
\end{tabular}

to the price to a highly significant degree. However, for four out of six quality categories examined, the quality difference between for-profit and non-profit nursing homes exists independent of the price charged. Therefore German for-profit nursing
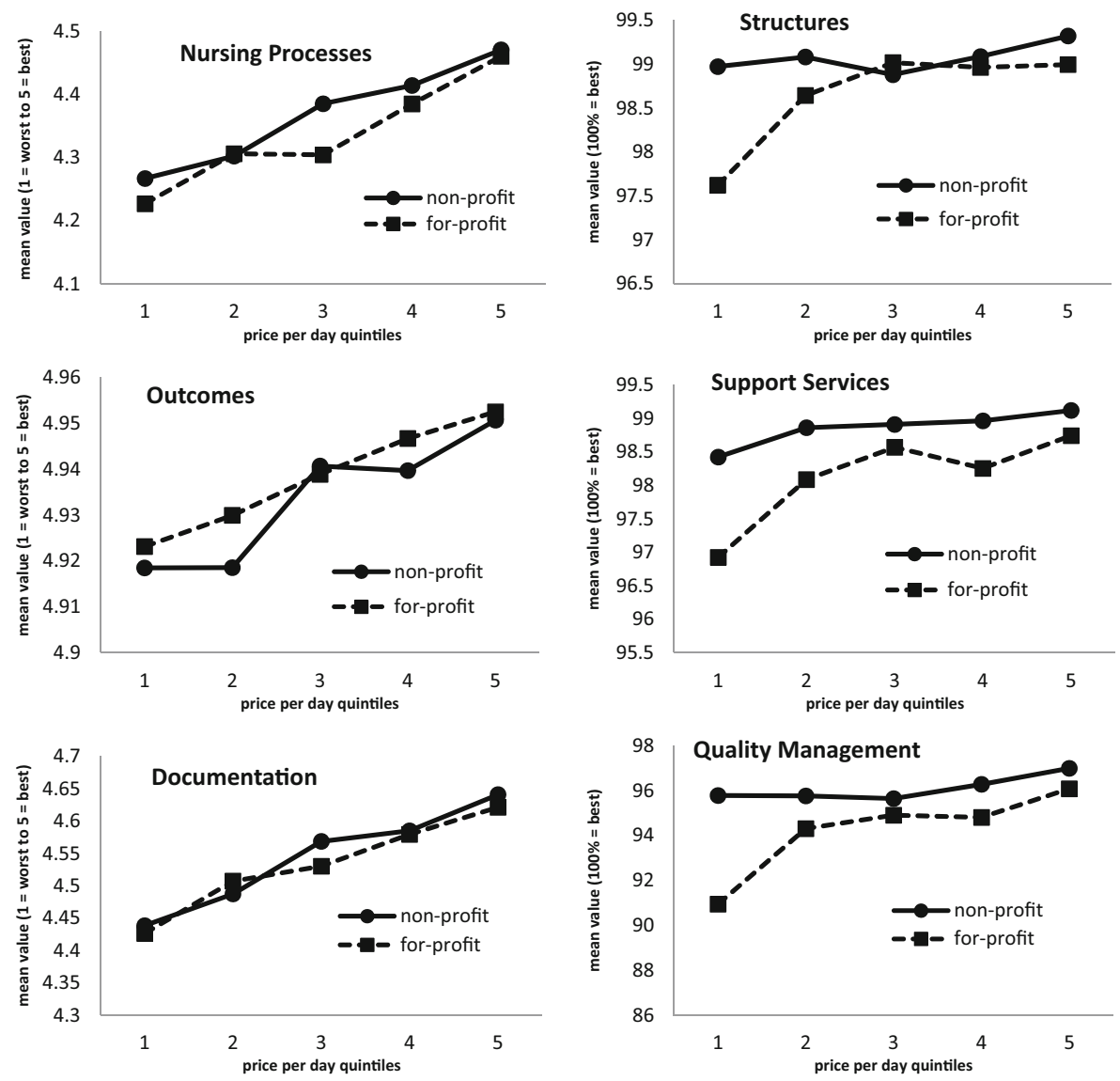

Fig. 1 Quality of care in six categories in relation to price per day and profit orientation of nursing homes in Germany $(N=10,168)$ (note that $\mathrm{Y}$-axis and $\mathrm{X}$-axis scaling varies) 
homes mainly appear to pursue the strategy of cost leadership described by M. Porter (1980) and accept the quality concessions involved.

Study results from Germany confirm findings described in the international literature which also identified a lower level of quality in for-profit nursing homes (Comondore et al. 2009, Harrington et al. 2012, Harrington et al. 2015). Also confirmed are results from a German study which found a correlation between prices charged by nursing homes and the quality of services provided when examining a smaller sample size of nursing homes (Mennicken 2013). A new finding from the present study is that quality differences between German nursing homes exist independent of the price. In the lower price bracket in particular, the average quality of for-profit nursing homes was found to be considerably below the quality in non-profit nursing homes of the same segment, whereas almost no differences between nursing homes were found in the upmost price segment in relation to profit orientation.

An analysis of the reported interaction between prices charged by nursing homes and their profit orientation suggests the following interpretation: specifically in the case of for-profit homes, it is worth selecting a nursing home from a higher price category to hope that the level of quality will be comparable to the care in non-profit homes. In the case of non-profit facilities, however, the price charged plays a minor role only in terms of quality. The lowest price category has many nursing homes that offer quality of the highest level.

Limitations Several limitations must be considered in the interpretation of study results. First, the design of a cross-sectional study does not permit to establish a causal relation. It is true that the quoted economic theories of Porter (1980) and Hansmann (1980) suggest the existence of such a relation. But the study design only permits to ascertain that the average for-profit nursing home in Germany, the same as elsewhere, offers services of a lower quality compared to non-profit institutions. The question remains open as to whether profit orientation is responsible for this fact.

An important limitation is inherent in the system of assessing nursing home quality in Germany. The majority of assessment criteria have a low discriminative potential, so that almost all nursing homes receive good to very good ratings. Moreover, outcome quality is hardly ascertained. Because the outcome measures did not show differences in facilities, perhaps the outcome measures should be reexamined for reliability and validity to determine whether they can distinguish quality among facilities. These points of criticism have been raised in Germany for years (Hasseler et al. 2010). But a partial revision of the catalogue of criteria has not included a comprehensive reform of assessment procedures which was repeatedly postponed by health politicians in the past. Pending this revision, researchers depend on the data available. Thanks to the fact that a full assessment of all nursing homes and an unbiased large-scale sample was available for analysis, it was nevertheless possible to statistically secure quality differences between nursing homes associated with profit orientation.

Another limiting aspect was the impossibility to consider the distribution of nursing requirements among residents of each home in the analysis since no pertinent data were available. All nursing homes were therefore assumed to have an individual distribution of care levels corresponding to the national average, i.e., approximately $40 \%$ of residents assigned to care levels one and two, and $20 \%$ to care level three. It is unlikely that this distribution differs between for-profit and non-profit homes in Germany in such 
a way that for-profit nursing homes have more residents in need of intensive nursing care. This is why it may be assumed that differing compositions of residents in terms of care levels do not explain quality differences in relation to profit orientation.

A methodological limitation is the fact that requirements for the multivariate variance analysis employed in the study were not met. On the one hand, there was no multivariate normal distribution; on the other, it was unclear whether the variancecovariance matrices were sufficiently homogeneous. It may be stated that there was a high robustness in terms of the alpha error in view of the large sample available. Moreover, additional non-parametric tests yielded the same results so that the MANOVA results may be interpreted in the presented form.

\section{Conclusions}

For-profit nursing homes in Germany, as shown in other countries, offer a lower level of quality compared to non-profit homes. The price charged by nursing facilities is related to quality: higher quality can be expected for higher prices, which applies mainly to forprofit facilities. When selecting a nursing home it is therefore advisable to consider the profit orientation of the institution. German legislation should require that statutory public quality reports contain details on the profit orientation of nursing homes, which is reported on the U.S. government's nursing home quality report card (CMS 2015).

Acknowledgments We thank the nursing division of the national sickness fund association AOK for the provision of data, and Mrs. Christina Wagner for support in translating the manuscript.

\section{Compliance with ethical standards}

Conflict of interest There are no competing interests to declare in relation to this manuscript.

Informed Consent The study did not require ethics committee approval since no personal data were analysed and the assessment of nursing homes was anonymous.

Ethical Treatment of Experimental Subjects (Animal and Human) This article does not contain any studies with human or animal subjects performed by any of the authors.

Open Access This article is distributed under the terms of the Creative Commons Attribution 4.0 International License (http://creativecommons.org/licenses/by/4.0/), which permits unrestricted use, distribution, and reproduction in any medium, provided you give appropriate credit to the original author(s) and the source, provide a link to the Creative Commons license, and indicate if changes were made.

\section{References}

Comondore, V. R., Devereaux, P. J., Zhou, Q., Stone, S. B., Busse, J. W., Ravindran, N. C., et al. (2009). Quality of care in for-profit and not-for-profit nursing homes: systematic review and meta-analysis. British Medical Journal, 339, b2732.

Geraedts, M., Heller, G. V., \& Harrington, C. A. (2000). Germany's long-term care insurance: putting a social insurance model into practice. Milbank Quarterly, 78/3, 375-401. 
GKV-Spitzenverband (2008). Pflege-Transparenzvereinbarung nach § 115 Abs. 1a Satz 6 SGB XI zur stationären Pflege - Anlage 1 - Kriterien der Veröffentlichung. Retrieved July 27, 2015 from http:// www.pflegenoten.de/media/dokumente/vereinbarungen/stationaere_vereinbarungen/09-09-25 Vereinbarung_stationaer_Anlage_1_Stand_17_12_2008_formell_ueberarbeitet.pdf.

Hansmann, H. B. (1980). The role of nonprofit enterprise. The Yale Law Journal, 89/5, 835-901.

Harrington, C., Olney, B., Carrillo, H., \& Kang, T. (2012). Nurse staffing and deficiencies in the largest forprofit nursing home chains and chains owned by private equity companies. Health Services Research, 47, $106-28$

Harrington, C., Ross, L. \& Kang, T. (2015). Hidden owners, hidden profits, and poor nursing home care: a case study. International Journal of Health Services. doi:10.1177/0020731415594772.

Hasseler, M., Wolf-Ostermann, K., Nagel, M. \& Indefrey, S. (2010). Wissenschaftliche Evaluation zur Beurteilung der Pflege-Transparenzvereinbarungen für den ambulanten (PTVA) und stationären (PTVS) Bereich. Empfehlungen des Beirates zur Evaluation der Pflege-Transparenzvereinbarungen. Berlin, 21. Juli 2010, p.85. Retrieved July 27, 2015 from http://www.pflegenoten.de/media/dokumente/ weiterentwicklung/Pflegenoten_Endbericht_Beirat_u_WB_2010_07_21.pdf.

Medicare Advocacy (2015). Retrieved July 27, 2015 from http://www.medicareadvocacy.org/non-profit-vsfor-profit-nursing-homes-is-there-a-difference-in-care/

Mennicken, R. (2013). Prices and quality in nursing homes - first empirical results for Germany. Gesundheitswesen, 75, 99-101.

Porter, M. E. (1980). Competitive strategy - techniques for analyzing industries and competitors. New York: Free Press.

Statistisches Bundesamt (2001). Kurzbericht: Pflegestatistik 1999 - Pflege im Rahmen der Pflegeversicherung - Deutschlandergebnisse. Retrieved July 27, 2015 from http://www.carelounge.de/pflegeberufe/politik/ studien_enquetepflege_Pflegestatistik99.pdf

Statistisches Bundesamt (2014). Pflegestatistik 2013, Deutschlandergebnisse. Retrieved July 27, 2015, from https://www.destatis.de/DE/Publikationen/Thematisch/Gesundheit/Pflege/ PflegeDeutschlandergebnisse5224001139004.pdf

US Centers for Medicare and Medicaid Services. (2015). Medicare nursing home compare. Retrieved August 31, 2015, from https://www.medicare.gov/nursinghomecompare/search.html

Max Geraedts MD, MPH, is Professor and Chair of the Institute for Health Systems Research at the School of Medicine, Faculty of Health, Witten/Herdecke University, Germany.

Charlene Harrington RN, PhD, FAAN, is a Professor emerita of sociology and nursing in the Department of Social and Behavioral Sciences in the School of Nursing at the University of California, San Francisco.

Daniel Schumacher MA, was at the time of the study a student of business administration at the Faculty of Management and Economics of Witten/Herdecke University, Germany.

Rike Kraska Dipl. Stat., is a research associate and PhD candidate at the Institute for Health Systems Research at the School of Medicine, Faculty of Health, Witten/Herdecke University, Germany. 